\title{
Use of Paper Microdevices in the Identification and Quantification of Cocaine in Seized Street Samples
}

\author{
Jadson Zeni dos Reis, Wanderson Romão* $\mathbb{D}$ \\ Laboratório de Petroleômica e Forense, NCQP, Universidade Federal do Espírito Santo, 29075-910, Vitória, ES, \\ Brazil
}

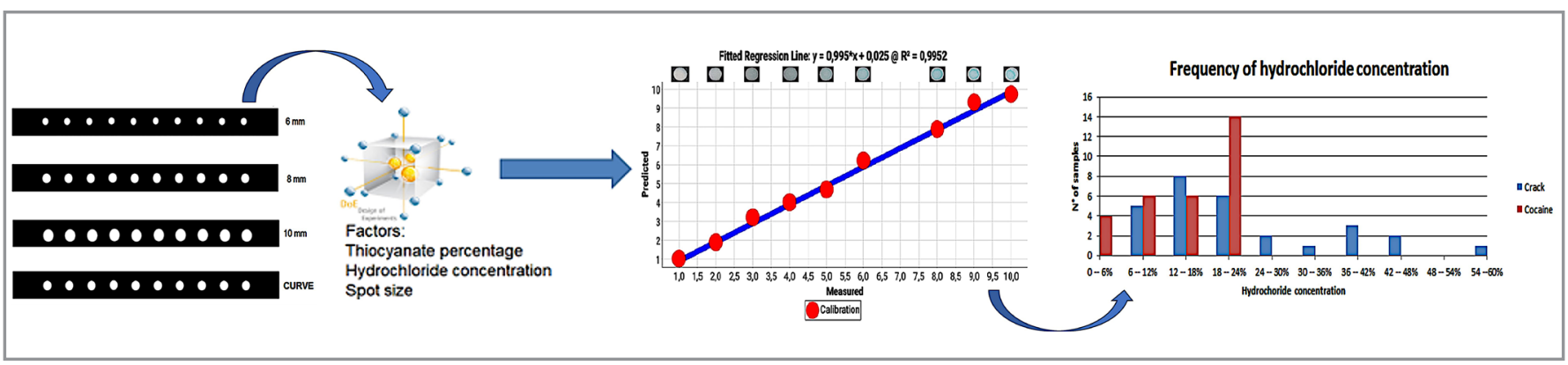

The growing consumption of illicit drugs in Brazil is becoming increasingly problematic for society. It is therefore critical to develop technologies to combat drug trafficking that allow for rapid, non-invasive evaluation of drug samples. Microfluidics is a technology that manipulates and studies small amounts of fluids, using structures with dimensions from ten to hundreds of micrometers (microdevices). The main advantages of microfluidic approaches are its low cost, speed, and ability to provide results in loco. Here, paper microfluidics were developed to perform the modified Scott test to calculate the cocaine hydrochloride content in seized samples of cocaine $(n=30)$ and crack $(n=30)$. A smartphone with the Photometrix ${ }^{\circledR}$ app was used to construct a model for quantifying the samples. A factorial model was developed to optimize microfluidic analytical parameters such as spot size $(6,8$ and $10 \mathrm{~mm})$, reagent content $(50,75$, and $100 \%$ cobalt thiocyanate II), cocaine hydrochloride concentration $\left(4,6\right.$ and $8 \mathrm{mg} \mathrm{mL}^{-1}$ ) and response time (or analyte detection; $\mathrm{t}=0,0.5,1,12$ and $24 \mathrm{~h}$ ). After experimental planning, a diameter of MPADs $=8 \mathrm{~mm}-$ $\left[\mathrm{Co}(\mathrm{SCN})_{2}\right]=100 \%$ and a $1 \mathrm{~h}$ response time were identified as the best conditions. We observed that the cocaine hydrochloride concentration did not influence the model. A sample concentration of $15 \mathrm{mg} \mathrm{mL}^{-1} \mathrm{was}$ used to quantify cocaine hydrochloride in street samples apprehended by the Forensic Police of Espírito Santo state (with $n=60$ ). The quantification curve constructed to determine the cocaine hydrochloride concentration showed a determination coefficient, $\mathrm{R}^{2}$, of 0.98246 and RMSEC (root mean squares error calibration - mean square error of the calibration) of 0.39480 , with a LOD and LOQ of 0.09 and $0.30 \mathrm{mg}$ $\mathrm{mL}^{-1}$, respectively. For the crack samples, the cocaine hydrochloride concentrations ranged from 2.5 to $60.8 \mathrm{wt} \%$ with an average purity content of $21.3 \pm 13.3 \mathrm{wt} \%$. For the seized cocaine samples, variation in hydrochloride content from 1.2 to $22.6 \mathrm{wt} \%$ was observed with a mean percentage of $14.19 \pm 6.92 \mathrm{wt} \%$. Finally, chemometric tools such as principal component analysis were used to assess the similarity among the samples.

Cite: dos Reis, J. Z.; Romão, W. Use of Paper Microdevices in the Identification and Quantification of Cocaine in Seized Street Samples. Braz. J. Anal. Chem., 2022, 9 (34), pp 118-137. doi: http://dx.doi.org/10.30744/brjac.2179-3425.AR-18-2021 
Keywords: cocaine, crack, microfluidic, Chemometrics, Photometrix ${ }^{\circledR}$.

\section{INTRODUCTION}

The commonly abused substances that cause psychological and physical dependence can be grouped into three major classes according to their main actions on the central nervous system (CNS): CNS depressants, CNS stimulants, and CNS disruptors. CNS depressants reduce brain activity and also have analgesic properties. People under the influence of these drugs become drowsy, lazy, careless, and unfocused. Among the main substance classes are highlighted: opioids, ethanol and barbiturates. CNS stimulants, which increase brain activity, accelerate the activity of particular neuronal systems, producing an exaggerated state of alertness, and insomnia. Cocaine, amphetamines, and methamphetamines (such as MDMA), and anorectic are examples of CNS stimulants. CNS disruptors distort brain functioning, producing altered states such as delusions, hallucinations, and changes in sensory perception. For this reason, CNS disruptors are also referred to as hallucinogens. Examples of CNS disruptors include LSD, psilocybin, mescaline, and cannabinoids [1-5].

Among these drugs, the cocaine, that is composed of a tropane alkaloid, inhibits the action of acetylcholine. Cocaine has a high local anesthetic action and is a potent stimulant of the central nervous system [6]. Cocaine belongs to the family of alkaloids (compounds with aromatic nitrogen) obtained from the leaves of the coca plant, Erythroxylum coca. The alkaloid content of the coca leaves varies according to different growing regions and varieties of the plant. The shrub grows in South America, particularly in Peru and Bolivia, and is found in the eastern Andes and above the Amazonic watershed. There are about 200 plant species, but only 17 of them are used for cocaine extraction and production. Cocaine can be consumed as salt, cocaine hydrochloride, or as a free base (crack) [7].

\section{Forensic sciences}

Forensic sciences are based on the concept that crimes cannot occur without producing some evidence, such as skin cell fragments, microscopic fibers, or a small amount of poison present in a drop of blood. Increasingly, forensic sciences have evolved to include the use of sensitive and precise instruments [8]. In this context, forensic chemistry is a branch of forensic science aimed at identifying material evidence for criminal justice proceedings, through the analysis of substances such as licit and illicit drugs, poisons, accelerants and fire residues, explosives, waste firearms, fuels, paints, and fibers [9]. These new technologies allow for efficient confirmation of crimes by laboratory analysis [10]. However, the ability to confirm samples in loco could solve several problems more quickly.

Chewing and ingesting coca leaves has been a common practice in South America for generations due to the stimulating effects of coca. However, cocaine purified from coca leaves is a schedule II drug since it has a high potential for abuse. In the street, cocaine has the appearance of a fine white powder and is mixed with a wide variety of adulterants, such as benzocaine, lidocaine, caffeine and procaine, in order to inflate the mass of the product, increasing profits from sales. For forensic identification of cocaine, it is common to use colorimetric kits that react to the presence of cocaine hydrochloride; however, these tests can be interfered with, producing false positive results. Other analytical techniques, including infrared spectroscopy by Fourier transform (ATRFTIR) and visible in ultraviolet (UV-VIS), can be used to confirm samples [11-13].

\section{Microfluidics}

Microfluidics, the study of the behavior of small fluid samples in small channels, has been applied in biochemical and pharmaceutical tests. However, a more detailed definition describes microfluidics as the science and technology of systems that manipulate and study small amounts of fluids, using structures (microdevices) with dimensions from tens to hundreds of micrometers [14].

To reduce the use of reagents and lower operating costs, microfluidics is increasingly being used in new equipment used in the chemical industry, and, consequently, in the forensic sciences. This trend is due 
to the increasing miniaturization of electronic devices. Miniaturization began in the 1960s, when analog devices began to be replaced by digital devices which have smaller dimensions but equivalent efficiency. The miniaturization of electronics is apparent when comparing a television from the 70 s with a current television or even when comparing a notebook to the first desktops [15].

In the 1990s, Manz et al. proposed the use of microsystems for total analysis, or simply $\mu$ TAS. With the development of $\mu$ TAS, it became possible to integrate in a single device several analytical steps, such as sample introduction, sample pre-treatment, chemical reactions, analytical separation, and detection $[16,17]$. Since several analytical steps, normally developed in a laboratory, were consolidated on a single chip, $\mu$ TAS are also called "lab-on-a-chip" (LOC) [14]. $\mu$ TAS, or LOC, transform chemical information into electrical or optical signals, enabling easy automation, becoming relevant to the clinical and environmental field in which the term "point-of-care" has been used $[14,18]$. These factors, coupled with portability, have driven the massive development of analytical microscale systems in recent years [19].

In the early 2000s, the 3D printer modified and accelerated the direction of microdevices. This technology uses a resin that stiffens in the presence of ultraviolet light, producing a sculpture perfectly aligned with the determinations indicated in specific computer programs. It is possible to easily create, for example, a channel system with micrometric measurements and printing.

New methods that use microfluidics for analysis have increased in number as 3D printing technology technique has become more popular. Among these innovations, paper-based microdevices stand out in terms of their low manufacturing cost and high portability.

\section{Microfluidic paper-based analytical devices ( $\mu P A D s)$}

Paper-based microfluidic devices (or $\mu$ PADs, from the term "microfluidic paper-based analytical devices") were created in 2007 by Martinez et al., from Harvard University. The purpose of these devices is to perform colorimetric sensing in a low-cost biological analysis. The paper is mainly composed of a cellulose polymer, which makes it porous, allowing it to favor the liquid fluidity between the fibers due to capillarity action [20].

Advantages to using paper for devices include the following: great abundance, low cost compared to other platforms for sensing, easy to obtain and handle, compatibility with large-scale production of microfluidic devices, possibility of long-term storage, easy physical modification and surface chemistry for bioassays, easy disposal through incineration making it more environmentally friendly, ability to use reduced volumes of samples (microliters to nanoliters depending on the resolution of the barriers created on the paper), and white color (suitable for colorimetric tests). However, some factors can also hinder the use of paper devices such a matrix effect, humidity and the homogeneity of the structure [21]. It is worth noting that substances such as benzocaine, lidocaine, caffeine, and procaine, if mixed with the samples, can generate a false positive result [13].

While there are clear advantages to using $\mu$ PADs for colorimetric analysis, there are some drawbacks. Applying $\mu \mathrm{PAD}$ technology cannot always be carried out directly, since pretreatment of the sample is necessary to avoid interference in the color of the solution, inconsistencies in lighting, lack of uniformity, or the presence of particulate contaminants that can confuse the interpretation of the colorimetric result. However, it is possible to couple these pretreatment processes in a single disposable paper device.

Wax printing is a method of producing $\mu$ PADs by depositing wax using solid ink printers. After printing, the paper must be heated to the melting point of the wax so that it penetrates through the cellulose fibers. Heating can be carried out with a heating plate, which is a common piece of equipment in laboratories. The use of $\mu \mathrm{PADs}$ as colorimetric sensors is already widespread in the scientific literature, such as research on monitoring acid-base titrations, food analysis, forensic analysis, and tumor biomarker identification [22-27].

\section{Smartphone app}

Growing technological advances have led to a dramatic increase in digital photographic technology, both in terms of software and hardware, which is expected to continue in the coming years due to the easiness and low cost of acquiring images through digital and smartphone cameras. The relationship 
between digital image and colorimetric tests favors obtaining both qualitative data and quantitative analytical measurements.

Digital images have been widely used to analyze food, beverages, fuels and other substances due to the low cost and speed of analysis and data collection. Studies to monitor and evaluate food quality, for example, are carried out visually where the use of digital image minimizes the recurrent subjectivity in these types of analyses. Digital images are matrices in which a point in the image is identified by lines and columns. The basic elements of this matrix are called pixels or image elements. Each pixel reports the intensity of the red, green, and blue colors, which are the three primary colors that produce different types of colors [28].

One of the software used is Photometrix ${ }^{\circledR}$, which is used for image processing in the quantification of chemical substances. This application was developed by Professor Gilson A. Helfer and collaborators at the University of Santa Cruz do Sul in Rio Grande do Sul [29].

\section{Use of chemometric tools}

One of the most important tools in the current development of analytical methods is the design of experiments, which helps to reduce the high variability of results, analysis times and the costs involved [30]. Routine applications of chemometric methods flow from analytical chemistry literature, such as in extraction methods, since there are several influential factors in this process.

Experimental planning seeks both to describe the experiment and to explicitly identify inferences about the causes of the process and/or the relationships of the conditions. This allows us to infer what we produced or contributed to these events. While several approaches can be used during experimental planning, the best approach is selected based on the type of evaluation or response. Thus, planning can be carried out using the factorial model, the fractional factorial, the Doehlert, the central compound (Central Composite Design - CCD), the Box-Behnken (Box-Behnken Design - BBD), among other approaches [31].

Principal component analysis (PCA) is a widely used chemometric technique in analytical chemistry that utilizes pattern recognition without supervision. Thus, PCA was used in this work to identify cluster formation, enabling the detection of anomalous samples [32]. In addition, PCA forms the basis for numerous processes of classification, pattern recognition and multivariate calibration [33].

PCA is used for classification, pattern recognition, and multivariate calibration processes [33]. PCA derives the analysis of multi-point principal components (multiway principal component analysis - MPCA). Thus, MPCA is an extension of PCA for data sets with a high degree of complexity, in which the data cube $X$ is unfolded in a matrix $X(i, j, k)$. PCA is a pattern recognition technique without supervision that allows the identification of natural cluster formation and the detection of anomalous samples [32]. Another technique applied in this work was partial least squares regression (PLS), a technique that reduces predictors to a smaller set of non-correlated components and performs least squares regression for these components in place of the original data. PLS regression is particularly useful when predictors are highly collinear or when there are more predictors than observations Because PLS does not assume that predictors are fixed, as opposed to multiple regressions, predictors can be measured in error, making PLS more robust to measurement uncertainty [34].

Thus, this work seeks to design and optimize $\mu$ PAD systems for the detection and quantification of cocaine. For this study, six factorial experimental designs with central points were developed using three different factors: spot diameter $(6,8$ and $10 \mathrm{~mm})$, cobalt II thiocyanate content $(50,75$ and $100 \%$ in relation to a standard commercial supply provided by the Civil Police of the state of ES, CP - ES), and concentration of cocaine hydrochloride $\left(4,6\right.$ and $\left.8 \mathrm{mg} \mathrm{mL}^{-1}\right)$, where a different sample exposure time was used to assess the stability of the system produced $(\mathrm{t}=0,0.5,1,12$, and $24 \mathrm{~h})$. With the aid of analytical tools such as ANOVAs, Pareto Graphs, and Response Surfaces, the factors will be optimized to determine the ideal point for the analysis. The light intensity recorded by the Photometrix ${ }^{\circledR}$ application will be compared to an analytical curve with nine points of known concentrations. In addition, chemometric tools such as PCA and PLS will be used to group and predict the cocaine hydrochloride content present in seized samples. 


\section{MATERIALS AND METHODS \\ Materials and reagents}

The MPADs were built with the aid of a ColorQube 8880 wax printer on a sheet of A4 paper. The standard solutions were prepared from $100 \mathrm{mg}$ of cocaine (standard produced by the Federal Police of Rio Grande do Sul). The photos were generated with a Samsung J8 Smartphone with a Photometrix ${ }^{\circledR}$ application. In total, 60 street samples were analyzed, including 30 of cocaine and 30 of crack.

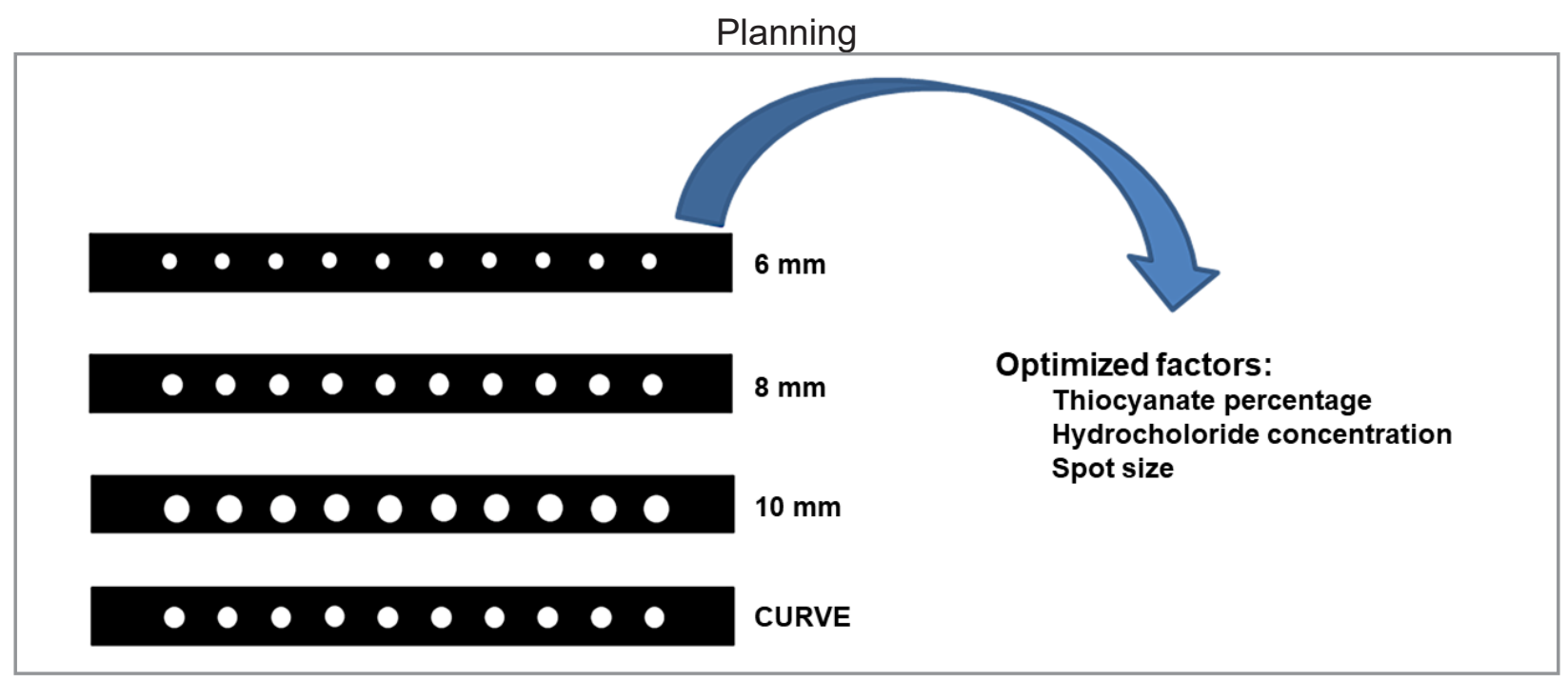

Figure1. Optimization of $\mu$ PADs.

MPADs were designed with the help of the Windows power point program. $\mu$ PADs of three different diameters - 6, 8 and $10 \mathrm{~mm}$ - were designed, since this was one of the factors studied with experimental planning. The ColorQube 8880 printer was used to print $\mu$ PADs on standard A4 chamex sheets. After printing, the sheet with the wax was fully impregnated with wax by placing the $\mu$ PADs in a greenhouse at $120^{\circ} \mathrm{C}$ for 5 minutes.

The standard solutions for the analytical curve for cocaine hydrochloride were prepared. Exactly 100 $\mathrm{mg}$ of sample was weighed and dissolved in $10 \mathrm{~mL}$ of ultrapure water. Using the prepared $10 \mathrm{mg} \mathrm{mL}^{-1} \mathrm{stock}$ solution, parts of the solution were diluted to prepare eight additional standards of different concentrations $-9,8,6,5,4,3,2$ and $1 \mathrm{mg} \mathrm{mL}^{-1}$ - which were used to construct the analytical curve. It is worth mentioning that constructing the analytical curve is important because it is another factor studied in planning - the influence of the cocaine hydrochloride concentration on the efficiency of the sensitivity of $\mu$ PADs. The third factor studied was the percentage of cobalt thiocyanate II, [Co(SCN $)_{2}$ ] added that could react with the drug. The original test uses the solution provided by the cooperation agreement, process 23068.011398/201272 , with the CP-ES. The study also assessed if the thiocyanate concentration increases the selectivity of the technique for cocaine. In this work, we tested 50,75 and $100 \%$ values relative to the standard solution provided by PC-ES [35].

With the prepared $\mu \mathrm{PADs}$ and the cocaine hydrochloride and [Co(SCN $\left.)_{2}\right]$ solutions, the next step was the construction of the experimental design. A factorial design was chosen, since there was no understanding of how each factor would influence the model. A total of six experiments were carried out. In the first, the factors chosen for planning were cocaine hydrochloride concentration, $\left[\mathrm{Co}(\mathrm{SCN})_{2}\right]$ concentration and the diameter of the $\mu P A D$, keeping the detection time fixed. In the first experiment, the detection time was defined as $\mathrm{t}=0 \mathrm{~s}$, and the colorimetric test images were acquired immediately after the experiment. For the other five time periods, the waiting time factor was treated in a unidimensional way with values of 30 min, 1 hour, 12 hours and 24 hours - waiting for the acquisition of images and analysis in the Photometrix ${ }^{\circledR}$ application. 
A factorial design was set up with three factors, totaling eight experiments, with three experiments added to the central point, totaling 11 experiments (see Table I).

Table I. Experimental factorial design with 3 factors

\begin{tabular}{ccccc}
\hline Test & Factor 1 & Factor 2 & Factor 3 & Answer $^{*}$ \\
\hline 1 & 100 & 10 & 8 \\
2 & 50 & 10 & 8 \\
3 & 100 & 6 & 8 \\
4 & 50 & 6 & 8 \\
5 & 100 & 10 & 4 \\
6 & 50 & 10 & 4 \\
7 & 100 & 6 & 4 \\
8 & 50 & 6 & 4 \\
9 & 75 & 8 & 6 \\
10 & 75 & 8 & 6 \\
11 & 75 & 8 & 6 \\
\hline
\end{tabular}

Factor 1 (\% of thiocyanate), Factor 2 (Diameter $(\mathrm{mm}))$ and Factor 3 (Cocaine Hydrochloride $\left(\mathrm{mg} \cdot \mathrm{mL}^{-1}\right)$ ). Answer * is the accuracy of the model in prediction of the cocaine concentration obtained by predicting whether the application curve matches the actual sample concentration.

Each experiment used $3 \mu \mathrm{L}$ of cocaine hydrochloride solution and $3 \mu \mathrm{L}$ of Cobalt II Thiocyanate solution provided by CP-ES. For example, in experiment $1,3 \mu \mathrm{L}$ of $100 \%$ of the $\left[\mathrm{Co}(\mathrm{SCN})_{2}\right]$ solution was pipetted, followed by waiting 5 minutes for the total and uniform impregnation of the $\mu$ PAD. Next, $3 \mu \mathrm{L}$ of hydrochloride solution was applied at a concentration of $8 \mathrm{mg} \mathrm{mL}^{-1}$. The other experiments were carried out using the same procedures. Following this, six experiments were built including one containing four factors, with the last factor being the waiting time for the response, which is used to determine the cocaine concentration using the Photometrix ${ }^{\circledR}$ app. In the other five schedules, the waiting time factor was treated in a unidimensional way with its waiting values $-t=0 \mathrm{~s}, 30 \mathrm{~min}, 1$ hour, 12 hours and 24 hours - for analysis with the Photometrix ${ }^{\circledR}$.

A PLS model was constructed using three different levels of concentrations and nine levels on the analytical curve. Since the concentrations of the solutions were known, the efficiency/accuracy-comparison between the measured and real values - was used as a response for each experiment performed, thus obtaining five plans.

\section{Analyzed samples}

With the planning completed and the analytical curve constructed, we analyzed the samples seized by the CP-ES, which included cocaine $(n=30)$ and crack $(n=30)$ samples.

Each sample was processed using the same procedure, in which a mass of $30 \mathrm{mg}$ was dissolved in $2 \mathrm{~mL}$ of ultrapure water. After the construction of the $\mu$ PADs with $8 \mathrm{~mm}$ in diameter, $3 \mu \mathrm{L}$ was pipetted of $100 \%\left[\mathrm{Co}(\mathrm{SCN})_{2}\right]$ solution, where a total and uniform impregnation of the MPAD was carried out for five 
minutes, and then $3 \mu \mathrm{L}$ of solution was applied for each unknown sample. After 1 hour, the Photometrix ${ }^{\circledR}$ software was used to build the PLS model and predict the cocaine hydrochloride content in each sample.

Finally, a PCA analysis was performed in order to determine the similarity between the seized samples of cocaine and crack.

\section{Photometrix}

To analyze the data, the Photometrix ${ }^{\circledR}$ software developed by the chemometrics research group of the University of Santa Cruz do Sul (RS, Brazil) was used. This software is available for free in the Android ${ }^{\circledR}$ and $\operatorname{IOS}^{\circledR}$ application store (http://www.photometrix.com.br). The software contains multivariate analysis tools and allows the user to perform principal component analysis (PCA), partial least squares regression (PLS), and hierarchical cluster analysis (HCA).

The application interface includes univariate and multivariate analyses. In the configuration interface, the user can determine the region of interest, camera settings, and register an email to export the data.

The PCA analysis method performed by the application was rapid and easy to carry out, with a few steps to the final data and without the need for image processing to interpret the results. For the construction of the graphs, channels R, G, B, H, S, V, L, and I was established with data centered on the mean.

To perform this test, the Samsung smartphone model J8 (16-megapixel camera, aperture F 1.7, digital stabilization, 4032x3024 pixel resolution and Android 8.1 operating system) was used. The samples were deposited in the MPADs followed by the reagents. After the pre-established time, a photo was taken with the $\mu$ PADs nailed to a white background. Then the data was processed.

\section{RESULTS AND DISCUSSION Experimental plans}

The experimental planning satisfied the imposed needs, allowing us to evaluate the best conditions to analyze the optimum concentration of cocaine hydrochloride. A total of six experiments were carried out as a result of five different times and a sixth planning in which the time was a fourth influential factor in the planning.

The analytical curve was constructed using the efficiency of the response obtained by the PLS model (Figure 5). Since the concentrations used at the three levels were known, the precision of the method that is, how close the actual concentration is to the model - was used as a response for the experiments. This analysis was based on the modified Scott test, a forensic screening test widely used to identify cocaine hydrochloride, which was created by Scott in 1973 and modified by Fasanello and Higgins for analyzing crack samples. Scott's test, equation 1 , is performed using a solution of [Co $\left.(\mathrm{SCN})_{2}\right]$ in an acid medium, which produces a blue-colored cobalt II complex in the presence of cocaine hydrochloride [35].

$$
\begin{aligned}
& \mathrm{Co}^{2+}+4 \mathrm{SCN}^{-}+2 \mathrm{~B}: \leftrightarrow \underset{\text { Blue }}{\left[\mathrm{Co}(\mathrm{SCN})_{4} \mathrm{~B}_{2}\right]^{2-}} \quad \text { Equation } 1 \\
& \text { Pink }
\end{aligned}
$$

Of the points analyzed, $3 \mu \mathrm{L}$ was used from a $1 \mathrm{mg} \mathrm{mL}^{-1}$ solution, demonstrating that it is possible to produce a qualitative response to $3 \mu \mathrm{g}$ of cocaine hydrochloride sample at low cost. Figure 5 shows the analytical curve of the analysis.

With the result of the calibration, tables can be constructed with responses for each experiment (supplementary material). Pareto graphs (Figure 1S), ANOVAs (Table 1S), and response surfaces (Figures 2S and 3S) were constructed with the values obtained.

The ANOVAs assessed the fit of the models as well as the predictability of the models (supplementary material Table 1S). Two models with three factors with immediate waiting times $(\mathrm{t}=0 \mathrm{~min})$ and $(\mathrm{t}=30$ min) showed a lack of adjustment (supplementary material, Table $1 S-A$ and B). Thus, these models were discarded for analysis. Therefore, only other models were used in the study. 
The study was carried out based on the experimental design with $t=1$ hour, since the other times make the analysis unpracticable for a routine exam. However, the plans for $t=12 \mathrm{~h}$ and $24 \mathrm{~h}$ revealed that the image coloring became stable after a certain amount of time and was not influenced after $\mathrm{t}=1 \mathrm{~h}$. However, $\mu$ PADs can be stored for a longer time, making their use very versatile for possible counter-proof. This was demonstrated through the factorial planning of four factors, which confirmed that time is not an influential factor in the efficiency of the model's response (Pareto graph, Figure 2).

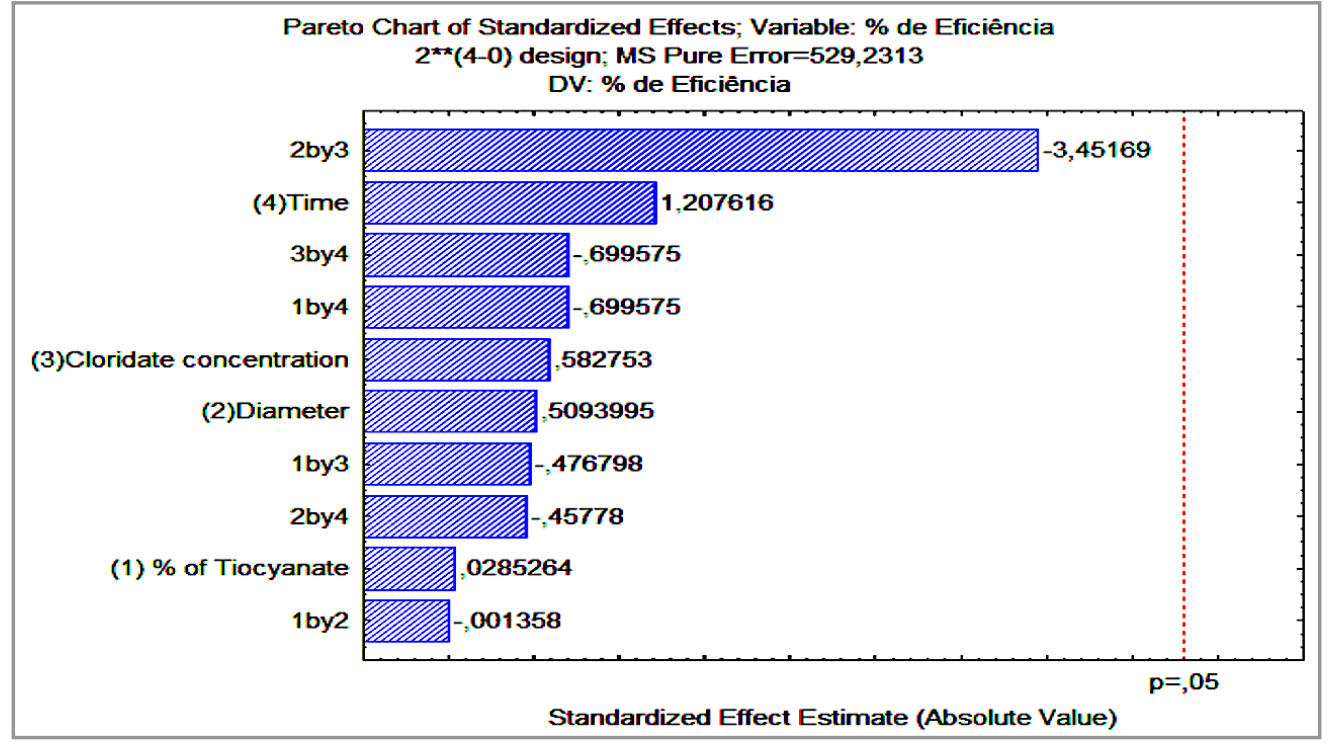

Figure 2. Pareto chart of planning with four factors.

The Pareto chart (supplementary material Figure $1 \mathrm{~S} \mathrm{C}-$ with $\mathrm{t}=1 \mathrm{~h}$ ) shows that the only influential factor is the concentration of hydrochloride in the sample in a negative form. It is due to its low concentration values, thus influencing, the photo resolution obtained that is directly proportional to the amount of revealed substance.

Thus, determining the response surfaces (Figures $2 S$ and $3 S$ of the supplementary material) were helpful in choosing the optimal points of the model (Figure 3). As described, the choice of the ideal points for the analysis was decided by observing the best efficiencies for each factor, which are found around the central points towards the ends of the model.
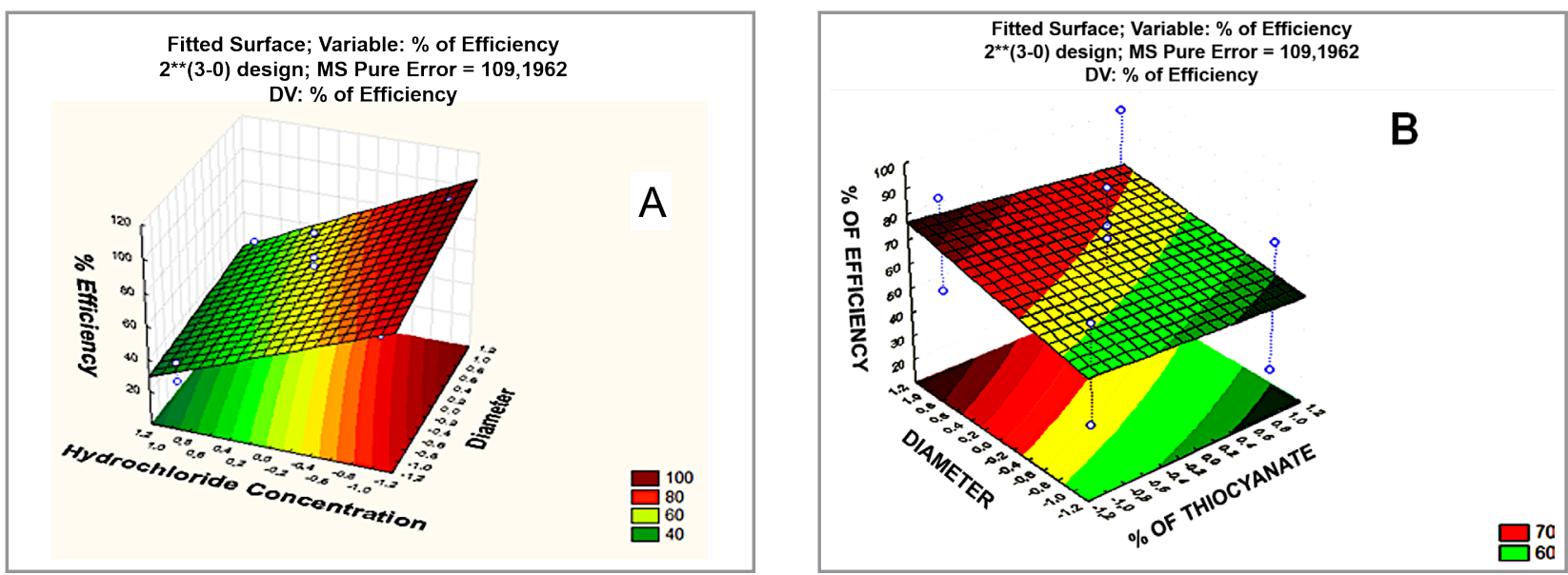

Figure 3. Response surfaces of hydrochloride concentration (A) versus spot diameter; and (B) spot diameter versus \% cobalt thiocyanate II. 
With the analytical parameters of $\mu \mathrm{PADs}$ defined, including diameter information $(8 \mathrm{~mm})$, the percentage of the cobalt thiocyanate II solution (100\%), and a response time of $1 \mathrm{~h}$, the quantification of cocaine hydrochloride in seized street samples $(n=60)$ was carried out. It is worth mentioning that for the use of the technique in the field, all this construction of MPADs is only necessary once, and can be updated over time in order to make the analysis more accurate. For daily use, it is only necessary to transport the printed sheet, being activated and already impregnated with the Cobalt II Thiocyanate reagent $\left[\mathrm{Co}(\mathrm{SCN})_{2}\right]$. Thus, the qualitative result is instantly generated with the gain of the preliminary quantitative analysis, in case of using the PLS model previously loaded in the application already installed on any smartphone.

\section{Seized samples}

The methodology used for the analyses was similar to the methodology previously discussed. All samples analyzed $(n=60)$ showed a positive response for the cocaine hydrochloride identification (Figure 4), and in some cases, the less intense bluish color is apparent (samples C16, C33, C35, and C44, for example) [13].

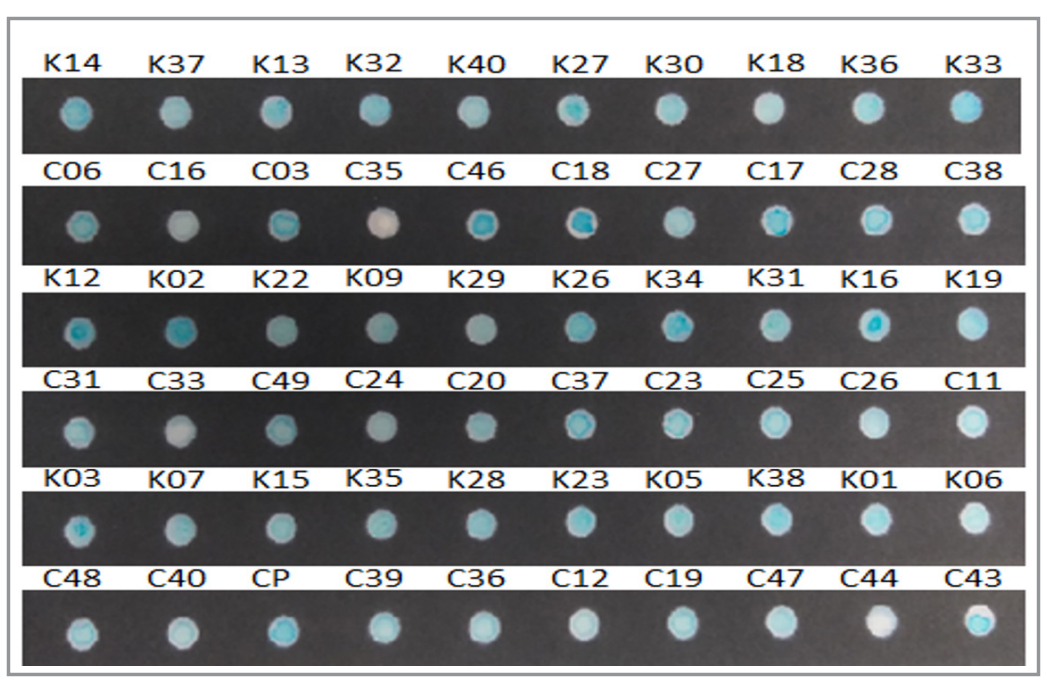

Figure 4. Result of the modified Scott test using the MPADs devices for seized samples of cocaine and crack.

The presence of a blue color confirms that the qualitative test has a good efficiency. According to the SWGDRUG recommendations, colorimetric tests are classified as $C$ class, being recommended as preliminary test. Therefore, it is necessary to perform other chemical analysis that are classified as A or B (NMR, GC-MS, LC-MS, etc.). However, the positive result for the colorimetric analysis allows to conclude negative results, being valid as an initial proof and opening precept for flagrante delicto. Traditional colorimetric analysis requires cobalt thiocyanate II reagent and is normally applied to solid samples, being difficulty its detection in dark liquids such as wines and grape juices. Hence, the technique presented herein uses volumes so small of the analyte that even when dissolved, the contrast with the white of the leaf allows to obtain visually positive results. Thus, the main gain for the insertion of this analysis in the forensic scope with a simple preparation, having the possibility of preliminary identification even the samples being dissolved in dark liquids [36]. Each spot of $\mu \mathrm{PAD}$ consumes only $3 \mu \mathrm{L}$ of aqueous solution, with virtually no sample loss. 


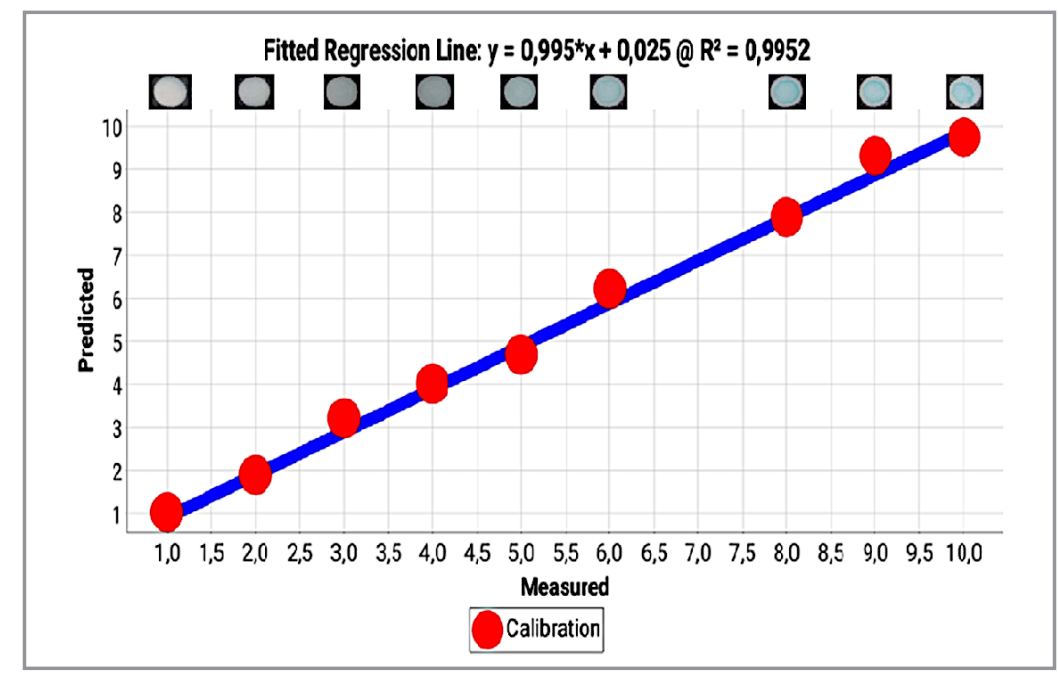

Figure 5. Cocaine hydrochloride analytical curve constructed by PLS.

The analytical curve and construction of a regression model for PLS was calculated (Figure 5). The curve produced a determination coefficient, $\mathrm{R}^{2}$, of 0.98246 , in addition to a RMSEC (root mean squares error calibration: mean square error of the calibration) of 0.39480 . The analytical curve generated a regression equation: $y=0.995 * x+0.025$ with a LOD and LOQ of $0.09 \mathrm{mg} \mathrm{mL}^{-1}$ and $0.30 \mathrm{mg} \mathrm{mL}^{-1}$, respectively [37].

For the crack samples, the hydrochloride concentrations ranged from 2.5 to $60.8 \mathrm{wt} \%$ with a mean average of $21.3 \pm 13.3 \mathrm{wt} \%$ (Table II).

Table II. Hydrochloride concentrations ( $\mathrm{mg} \mathrm{mL}^{-1}$ and wt\%) in crack samples

\begin{tabular}{|c|c|c|c|c|c|}
\hline Sample & $\left(\mathrm{mg} \mathrm{mL}^{-1}\right)$ & wt $\%$ & Sample & $\left(\mathrm{mg} \mathrm{mL}^{-1}\right)$ & $w t \%$ \\
\hline K14 & 9.12 & 60.8 & K26 & 1.35 & 9.00 \\
\hline K37 & 6.14 & 40.94 & K34 & 2.96 & 19.74 \\
\hline K13 & 4.03 & 26.87 & K31 & 2.86 & 19.07 \\
\hline K32 & 6.81 & 45,40 & K16 & 2.34 & 15.60 \\
\hline K40 & 3.59 & 23.94 & K19 & 1.29 & 8.60 \\
\hline K27 & 6.89 & 45.94 & K03 & 2.08 & 13.87 \\
\hline K30 & 4.41 & 29,40 & K07 & 2.70 & 18.00 \\
\hline K37 & 6.14 & 40.94 & K34 & 2.96 & 19.74 \\
\hline K18 & 2.63 & 17.54 & K15 & 1.94 & 12.94 \\
\hline K36 & 5.06 & 33.74 & K35 & 1.51 & 10.07 \\
\hline K33 & 5.73 & 38.20 & K28 & 2.83 & 18.87 \\
\hline K12 & 1.76 & 11.74 & K23 & 2.32 & 15.47 \\
\hline K02 & 0.37 & 2.47 & K05 & 1.66 & 11.07 \\
\hline K22 & 2.03 & 13.54 & K38 & 0.54 & 3.60 \\
\hline K09 & 2.79 & 18.60 & K01 & 1.97 & 13.14 \\
\hline
\end{tabular}


For the seized cocaine samples, the hydrochloride content variated from 1.2 to $22.6 \mathrm{wt} \%$, with an average cocaine hydrochloride percentage of approximately $14.19 \pm 6.92 \mathrm{wt} \%$ (Table III), similar to values previously reported in the literature [13]. It is important to note that the hydrochloride values present in the seized samples may indicate cocaine as well as some impurities such as adulterants like lidocaine and phenacetin. Previous evidence has shown that the Scott test provides false-positive results for these two substances [38]. However, it is important to note that, like the traditional method of analysis, the technique applied in this work is not able to differentiate interfering substances. On other hand, colorimetry test in microfluids scale allows to produce qualitative and quantitative results simultaneously, with minor sample preparation, lower cost than the traditional one and being less environmentally invasive, since uses much less sample and is based on a sheet of paper.

Table III. Hydrochloride concentrations ( $\mathrm{mg} \mathrm{mL}^{-1}$ and $\mathrm{wt} \%$ ) in cocaine samples

\begin{tabular}{|c|c|c|c|c|c|}
\hline Sample & $\left(\mathrm{mg} \mathrm{mL}^{-1}\right)$ & wt $\%$ & Sample & $\left(m g \mathrm{~mL}^{-1}\right)$ & wt \% \\
\hline C06 & 0.97 & 6.47 & $\mathrm{C} 37$ & 1.19 & 7.94 \\
\hline C16 & 3.39 & 22.60 & $\mathrm{C} 23$ & 2.95 & 19.67 \\
\hline $\mathrm{CO} 3$ & 0.19 & 1.27 & $\mathrm{C} 25$ & 3.00 & 20.00 \\
\hline C35 & 3.22 & 21.47 & $\mathrm{C} 26$ & 3.11 & 20.74 \\
\hline C46 & 1.01 & 6.74 & C11 & 2.16 & 14.40 \\
\hline C18 & 1.02 & 6.80 & C48 & 2.19 & 14.60 \\
\hline C27 & 2.75 & 18.34 & C40 & 2.92 & 19.47 \\
\hline C17 & 1.94 & 12.94 & $\mathrm{CP}$ & 1.23 & 8.20 \\
\hline $\mathrm{C} 28$ & 0.22 & 1.47 & C39 & 1.56 & 10.40 \\
\hline C38 & -0.13 & -0.87 & C36 & 3.04 & 20.27 \\
\hline C31 & 0.74 & 4.94 & C12 & 2.79 & 18.60 \\
\hline C33 & 3.19 & 21.27 & C19 & 2.33 & 15.54 \\
\hline C49 & 2.54 & 16.94 & C47 & 3.25 & 21.67 \\
\hline C24 & 2.86 & 19.07 & C44 & 3.07 & 20.47 \\
\hline $\mathrm{C} 20$ & 2.29 & 15.27 & C43 & 2.87 & 19.14 \\
\hline
\end{tabular}

Figure 6 shows a graph of the frequency of the concentration of hydrochloride for cocaine and crack samples, showing a higher concentration present in crack samples: 14 samples had concentrations ranging from 18 to $24 \mathrm{wt} \%$, while cocaine samples, had concentrations ranging from 12 to $18 \mathrm{wt} \%$, similar to street sample values previously reported [38]. 


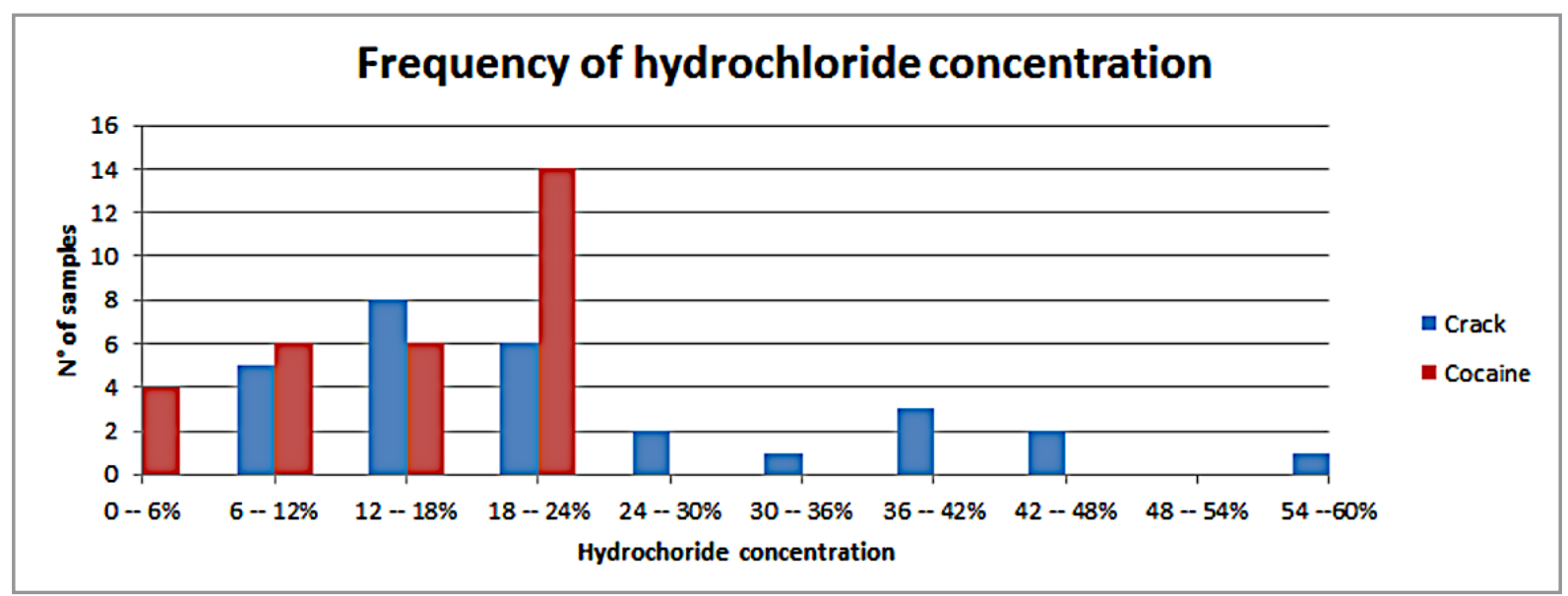

Figure 6. Frequency graph of hydrochloride concentrations for cocaine and crack samples.

Finally, PCA analysis was performed using 60 street samples, which were classified into two groups: cocaine (identified by "C") and crack ("K"; see Figure 7). Selection of the PC1 vs PC3 plot was based on the best visualization of separation of the groups. The K13, K27, K30, K32, K36, K37 and K40 samples (with [hydrochloride] from 27 to $45 \mathrm{wt} \%$ ), which have a higher content of cocaine, were grouped together, analyzing the PC1>0 region. The first component separated the groups in an acceptable way and was responsible for explaining of more than $50 \%$ of variance; this component probably represents the hydrochloride content in the sample. The PC1 vs PC2 and PC2 vs PC3 plots did not clearly group the samples, therefore these plots are not shown.

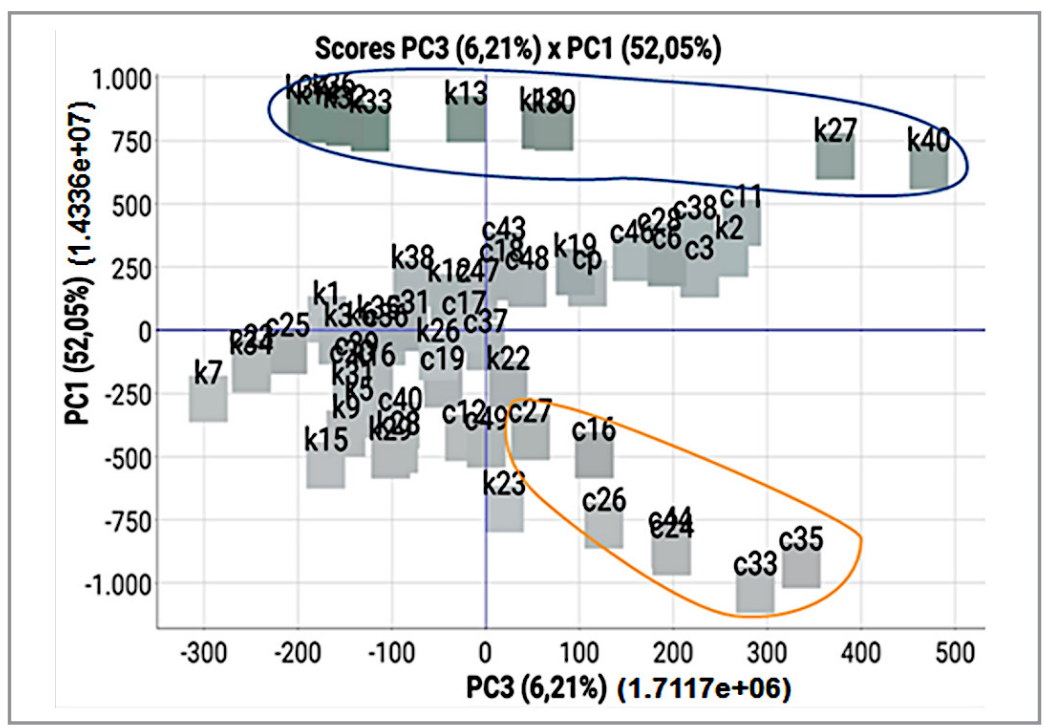

Figure 7. PC1 vs PC3 plot for cocaine and crack (represented by $C_{n}$ and $K_{n}$ symbols, respectively. With the loadings that explain $80.6 \%$ of the variance.

In general, many seized cocaine samples were distributed around the center of the PC1 vs PC3 plot, likely indicating a lower concentration of cocaine. On the other hand, cocaine samples located in the $\mathrm{PC} 1<0$ region (samples C16, C23, C24, C26, C33, C35 and C44, with [hydrochloride] $\approx 20 \% \mathrm{w} / \mathrm{w}$ ) had similar analyte concentrations. Therefore, PC1 was capable of separating samples into three large groups based on the concentration of cocaine hydrochloride present. 


\section{CONCLUSIONS}

In this work, choosing effective experimental designs saved hours of variation in factors, countless experiments as well as saving on reagents. The samples were preserved well, since there was a loss of approximately $3 \mu \mathrm{g}$ per sample analyzed. The accuracy of the concentration can only be confirmed by cataloged analysis.

As our results show, it is possible to quickly classify samples as crack or cocaine. In addition, an analytical curve with $\mathrm{R}^{2}$ greater than 0.98 with hydrochloride content variated from 1.2 to $22.6 \mathrm{wt} \%$, with an average percentage of approximately $14.19 \pm 6.92 \mathrm{wt} \%$ for street samples of cocaine. For crack samples, the hydrochloride concentrations ranged from 2.5 to $60.8 \mathrm{wt} \%$ with a mean average of $21.3 \pm 13.3 \mathrm{wt} \%$.

These findings demonstrate that MPAD is a useful approach for analyzing cocaine and crack samples. This analytical approach is still evolving, given the possibility of combining this approach with high-tech resources such as a smartphone. It is also important to note that the financial savings of the analysis is satisfactory, since the application is free and the possibility of up to 70 analyzes on a sheet of plain paper has already been proven, requiring only wax printing, at a standard cost of 25 cents per sheet, and activation in the greenhouse. In addition, the curves can be saved and incremented by new samples making the analysis more refined in the application, facilitating its application in loco. Thus, we present a quick, non-invasive analysis that allows the analysis of the substrate even dissolved in liquids.

\section{Conflicts of interest}

The authors declare no conflicts of interest.

\section{Acknowledgements}

The authors thank FAPES (EDITAL CNPq/FAPES No 23/2018 - Programa de Apoio a Núcleos Emergentes - PRONEM grant number 596/2018) and CNPq (422555/2018-5 and 305359/2017-7) for financial support. The authors would also like to thank the IFES (edital EDITAL PRPPG 07/2020) by funding the English grammar correction.

\section{REFERENCES}

1. United Nations, Brazil. Available at: https://nacoesunidas.org/29-milhoes-de-adultos-dependem-dedrogas-aponta-relatorio-do-unodc/ [Accessed 10 June 2019].

2. Rocha, W. W. F.; Leite, J. A.; Correia, R. M.; Tosato, F.; Madeira, N. C. L.; Filgueiras, P. R.; Lacerda Jr, V.; Freitas, J. C. C.; Romão, W.; Neto, A. C. Anal. Methods, 2018, 10 (15), pp 1685-1694 (https://doi. org/10.1039/C7AY03000B).

3. United Nations Office on Drugs and Crime (UNODC). World Drug Report, 2013. Available at: http:// www.unodc.org/unodc/secured/wdr/wdr2013/World_Drug_Report_2013.pdf [Accessed 30 March 2019].

4. United Nations Office on Drugs and Crime (UNODC), World Drug Report, 2017. Available at: http:// www.unodc.org/wdr2017/field/Booklet_1_EXSUM.pdf [Accessed 02 abril 2019].

5. Passagli, M. F. Toxicologia Forense: teoria e prática, $4^{\text {th }}$ Edition. Editora Millennium, Campinas, 2013.

6. Plowman, T.; Rivier, L. Annals of Botany, 1983, 51 (5), pp 641-659 (https://doi.org/10.1093/ oxfordjournals.aob.a086511).

7. Chitwood, D. D. Patterns and consequences of cocaine use. In: Kozel, N. J.; Adams, E. H. (Eds.) Cocaine Use in America: Epidemiologic and Clinical Perspectives. National Institute on Drug Abuse, NIDA Research Monograph 61, 1985, pp 111-129.

8. Lesney, M. S. Today's Chemist at Work, October 2004, pp 15-16. Available at: https://pubsapp.acs. org/subscribe/archive/tcaw/13/i10/pdf/1004instruments.pdf [Accessed June 2021].

9. Romão, W.; Schwab, N. V.; Bueno, M. I. M. S.; Sparrapan, R.; Eberlin, M. N.; Martiny, A.; Sabino B. D.; Maldaner, A. O. Quim. Nova, 2011, 34 (10), pp 1717-1728 (https://doi.org/10.1590/S010040422011001000005). 
10. Sabino, B. D.; Romão, W.; Sodré, M. L.; Correa, D. N.; Pinto, D. B. R.; Alonso, F. O. M.; Eberlin, M. N. Am. J. Anal. Chem., 2011, 2 (6), pp 658-664 (https://doi.org/10.4236/ajac.2011.26075).

11. Calatayud, J.; González, A. Anesthesiology, 2003, 98 (6) pp 1503-1508 (https://doi. org/10.1097/00000542-200306000-00031).

12. Goldstein, R. A.; DesLauriers, C.; Burda, A.; Johnson-Arbor, K. Seminars in Diagnostic Pathology, 2009, 26 (1), pp 10-17 (https://doi.org/10.1053/j.semdp.2008.12.001).

13. Conceição, V. N.; Souza, L. M.; Merlo, B. B.; Filgueiras, P. R.; Poppi, R. J.; Romão, W. Quim. Nova, 2014, 37 (9), pp 1538-1544 (https://doi.org/10.5935/0100-4042.20140240).

14. Martinez, A. W.; Phillips, S. T.; Butte, M. J.; Whitesides, G. M. Angew. Chem., Int. Ed., 2007, 46, pp 1318-1320 (https://doi.org/10.1002/ange.200603817).

15. Terry, S. C.; Jerman, J. H.; Angell, J. B. IEEE Trans. Electron Devices, 1979, 26 (12), pp 1880-1886 (https://doi.org/10.1109/T-ED.1979.19791).

16. Manz, A.; Graber, N.; Widmer, H. M. Sens. Actuators, B, 1990, 1 (1-6), pp 244-248 (https://doi. org/10.1016/0925-4005(90)80209-I).

17. Lo, R. C. Chem. Eng. Process Tech., 2013. Available at: http://www.jscimedcentral.com/ ChemicalEngineering/Articles/chemicalengineering-1-1002.pdf [Accessed June 2021].

18. Coltro, W. K. T.; Piccin, E.; Carrilho, E.; Jesus, D. P.; Silva, J. A. F.; Silva, H. D. T.; Lago, C. L. Quim. Nova, 2007, 30 (8), pp 1986-2000 (https://doi.org/10.1590/S0100-40422007000800034).

19. Nguyen, N.-T.; Wereley, S. T.; Shaegh, S. A. M. Fundamentals and Applications of Microfluidics. Artech house, Norwood, MA, 2018.

20. Martinez, A. W.; Phillips, S. T.; Butte, M. J.; Whitesides, G. M. Angew. Chem., Int. Ed., 2007, 46 (8), pp 1318-1320 (https://doi.org/10.1002/anie.200603817).

21. Araujo, W. R. Development of electrochemical and colorimetric sensors for applications in forensic interest samples. Doctoral thesis, 2016, Institute of Chemistry, University of São Paulo, São Paulo, SP, Brazil (https://doi.org/10.11606/T.46.2016.tde-18082016-084906).

22. Garcia, P. T. Development of colorimetric and electrochemical sensors for clinical and forensic applications. Doctoral thesis, 2017, Universidade Federal de Goiás, Goiânia, GO, Brazil (http:// repositorio.bc.ufg.br/tede/handle/tede/8180).

23. Krauss, S. T.; Holt, V. C.; Landers, J. P. Sens. Actuators, B, 2017, 246, pp 740-747 (https://doi. org/10.1016/j.snb.2017.02.018).

24. Hidayat, M. A.; Maharani, D. A.; Purwanto, D. A.; Kuswandi, B.; Yuwono, M. Biotechnol. Bioprocess Eng., 2020, 25 (2), pp 255-263 (https://doi.org/10.1007/s12257-019-0299-8).

25. Balu, B.; Berry, A. D.; Hess, D. W.; Breedveld, V. Lab on a Chip, 2009, 9 (21), pp 3066-3075 (https:// doi.org/10.1039/B909868B).

26. Caivano, S.; Ferreira, B. J.; Domene, S. M. A. Ciência \& Saúde Coletiva, 2014, 19, pp 1437-1446 (https://doi.org/10.1590/1413-81232014195.13932013).

27. Trinh, T. N. D.; Lee, N. Y. Lab on a Chip, 2019, 19 (8), pp 1397-1405 (https://doi.org/10.1039/ C8LC01389F).

28. Helfer, G. A.; Magnus, V. S.; Böck, F. C.; Teichmann, A.; Ferrão, M. F.; Costa, A. B. J. Braz. Chem. Soc., 2017, 28 (2), pp 328-335 ( https://doi.org/10.5935/0103-5053.20160182).

29. Button, S. T. Metodologia para Planejamento Experimental e Análise de Resultados. Mechanical Engineering Post Graduate Program Workbook, Mechanical Engineering Faculty, University of Campinas, 2005. Available at: http://www.fem.unicamp.br/ sergio1/pos-graduacao/IM317/apostila.pdf [Accessed June 2021].

30. Neto, B. B.; Scarminio, I. S.; Bruns, R. E. Como Fazer Experimentos: Pesquisa e Desenvolvimento na Ciência e na Indústria. Bookman, Porto Alegre, 2010.

31. Naef, R.; Jaquier, A.; Velluz, A.; Bachofen, B. Chemistry \& Biodiversity, 2004, 1 (12), pp 1870-1879 (https://doi.org/10.1002/cbdv.200490143). 
32. Moniruzzaman, M.; Rodríguez, I.; Ramil, M.; Cela, R.; Sulaiman, S. A.; Ganc, S. H. Talanta, 2014, 129, pp 505-515 (https://doi.org/10.1016/j.talanta.2014.06.019).

33. Geladi, P.; Kowalski, B. R. Anal. Chim. Acta, 1986, 185, pp 1-17 (https://doi.org/10.1016/00032670(86)80028-9).

34. Caligiorne, M. S.; Marinho, A. P. Revista Criminalística e Medicina Legal, 2016, 1 (1), pp 34-45.

35. Instituto Nacional de Metrologia, Normalização e Qualidade Industrial (INMETRO). De Acreditação, Coordenação Geral. Orientação sobre validação de métodos analíticos. Documento de carácter orientativo, 2010. Available at: http://www.inmetro.gov.br/credenciamento [accessed June 2021].

36. Silva, G. R. Perfil de drogas de abuso apreendidas e admitidas no Instituto de Polícia Científica entre os meses de janeiro a novembro de 2017. Trabalho de Conclusão de Curso, 2018, Centro de Ciências da Saúde, Universidade Federal da Paraíba, João Pessoa, PB, Brasil (https://repositorio.ufpb.br/jspui/ handle/123456789/17642).

37. Watson, S.; Chandler, N.; Howstuffworks: Manufacturing crack cocaine. Available at: https://science. howstuffworks.com/crack2.htm. [Accessed 28 January 2020].

38. Kiefer, S. Estudo mostra que cocaína comercializada em Minas é a mais "batizada" do Brasil. Estado de Minas Gerais, Belo Horizonte, 04/04/2014. Available at: https://www.em.com.br/app/noticia/ gerais/2014/04/04/interna_gerais,515369/estudo-mostra-que-cocaina-comercializada-em-minas-e-amais-batizada-do-brasil.shtml [Accessed 25 July 2020].

\section{SUPPLEMENTARY MATERIAL}

Table 1S. ANOVA of the six statistical models: Immediate (a), 30 min (b), 1 hour (c), 12 hours (d), 24 hours (e) and time as variable (f), respectively.

\begin{tabular}{lccccc}
\hline Factor & SS & df & MS & F & p \\
\hline (1) \% Thiocyanate & 244.76 & 1 & 244.76 & 5.11 & 0.15 \\
(2) Diameter & 4.13 & 1 & 4.13 & 0.08 & 0.8 \\
(3) Hydrochloride Concentration & 2664.5 & 1 & 2664.5 & 55.63 & 0.02 \\
1 by 2 & 144.5 & 1 & 144.5 & 3.01 & 0.22 \\
1 by 3 & 453.76 & 1 & 453.76 & 9.47 & 0.09 \\
2 by 3 & 79.69 & 1 & 79.69 & 1.66 & 0.33 \\
Lack of Fit & 2784.96 & 2 & 1392.48 & 29.07 & 0.03 \\
Pure Error & 95.79 & 2 & 47.89 & & \\
Total SS & 6472.1 & 10 & & & $\mathbf{A}$ \\
\hline
\end{tabular}


Table 1S. ANOVA of the six statistical models: Immediate (a), 30 min (b), 1 hour (c), 12 hours (d), 24 hours (e) and time as variable (f), respectively. (Continuation)

\begin{tabular}{|c|c|c|c|c|c|}
\hline Factor & SS & df & MS & $\mathbf{F}$ & $\mathbf{p}$ \\
\hline (1) \% Thiocyanate & 10.99 & 1 & 10.99 & 0.37 & 0.60 \\
\hline (2) Diameter & 1474.92 & 1 & 1474.92 & 49.15 & 0.02 \\
\hline (3) Hydrochloride Concentration & 295.55 & 1 & 295.55 & 9.85 & 0.09 \\
\hline 1 by 2 & 57.11 & 1 & 57.11 & 1.90 & 0.30 \\
\hline 1 by 3 & 16.89 & 1 & 16.89 & 0.56 & 0.53 \\
\hline 2 by 3 & 7773.49 & 1 & 7773.49 & 259.05 & 0.004 \\
\hline Lack of Fit & 2392.73 & 2 & 1196.36 & 39.87 & 0.02 \\
\hline Pure Error & 60.01 & 2 & 30.01 & & \\
\hline Total SS & 12081.69 & 10 & & & B \\
\hline Factor & SS & df & MS & $\mathbf{F}$ & $\mathbf{p}$ \\
\hline (1) \% Thiocyanate & 88.61 & 1 & 88.61 & 0.81 & 0.46 \\
\hline (2) Diameter & 310.94 & 1 & 310.94 & 2.85 & 0.23 \\
\hline (3) Hydrochloride Concentration & 5043.85 & 1 & 5043.85 & 46.19 & 0.02 \\
\hline 1 by 2 & 5.08 & 1 & 5.08 & 0.05 & 0.85 \\
\hline 1 by 3 & 254.53 & 1 & 254.53 & 2.33 & 0.27 \\
\hline 2 by 3 & 26.74 & 1 & 26.74 & 0.24 & 0.67 \\
\hline Lack of Fit & 1342.52 & 2 & 671.26 & 6.15 & 0.14 \\
\hline Pure Error & 218.40 & 2 & 109.20 & & \\
\hline Total SS & 7290.65 & 10 & & & C \\
\hline Factor & SS & df & MS & $\mathbf{F}$ & $p$ \\
\hline (1) \% Thiocyanate & 67.57 & 1 & 67.57 & 0.19 & 0.70 \\
\hline (2) Diameter & 47.53 & 1 & 47.53 & 0.13 & 0.75 \\
\hline (3) Hydrochloride Concentration & 2701.12 & 1 & 2701.12 & 7.68 & 0.11 \\
\hline 1 by 2 & 540.38 & 1 & 540.38 & 1.54 & 0.34 \\
\hline 1 by 3 & 4.13 & 1 & 4.13 & 0.01 & 0.92 \\
\hline 2 by 3 & 1188.28 & 1 & 1188.28 & 3.38 & 0.21 \\
\hline Lack of Fit & 1993.22 & 2 & 996.61 & 2.83 & 0.26 \\
\hline Pure Error & 702.87 & 2 & 351.44 & & \\
\hline Total SS & 7245.11 & 10 & & & $\mathbf{D}$ \\
\hline
\end{tabular}


Table 1S. ANOVA of the six statistical models: Immediate (a), 30 min (b), 1 hour (c), 12 hours (d), 24 hours (e) and time as variable (f), respectively. (Continuation)

\begin{tabular}{|c|c|c|c|c|c|}
\hline Factor & sS & df & MS & $\mathbf{F}$ & $\mathbf{p}$ \\
\hline (1) \% Thiocyanate & 450.00 & 1 & 450.00 & 0.56 & 0.53 \\
\hline (2) Diameter & 569.53 & 1 & 569.53 & 0.71 & 0.49 \\
\hline (3) Hydrochloride Concentration & 625.69 & 1 & 625.69 & 0.79 & 0.47 \\
\hline 1 by 2 & 1075.32 & 1 & 1075.32 & 1.35 & 0.36 \\
\hline 1 by 3 & 2295.03 & 1 & 2295.03 & 2.88 & 0.23 \\
\hline 2 by 3 & 55.12 & 1 & 55.12 & 0.07 & 0.82 \\
\hline Lack of Fit & 260.97 & 2 & 130.48 & 0.16 & 0.86 \\
\hline Pure Error & 1591.61 & 2 & 295.80 & & \\
\hline Total SS & 6923.28 & 10 & & & $\mathbf{E}$ \\
\hline Factor & SS & df & MS & $\mathbf{F}$ & $\mathbf{p}$ \\
\hline (1) \% Thiocyanate & 0.43 & 1 & 0.43 & 0.0008 & 0.98 \\
\hline (2) Diameter & 137.33 & 1 & 137.33 & 0.26 & 0.66 \\
\hline (3) Hydrochloride Concentration & 179.73 & 1 & 179.73 & 0.34 & 0.62 \\
\hline (4) Thiocyanate Time & 771.80 & 1 & 771.80 & 1.46 & 0.35 \\
\hline 1 by 2 & 0.001 & 1 & 0.001 & 0.00 & 1.00 \\
\hline 1 by 3 & 120.31 & 1 & 120.31 & 0.28 & 0.68 \\
\hline 1 by 4 & 259.01 & 1 & 259.01 & 0.49 & 0.56 \\
\hline 2 by 3 & 6305.35 & 1 & 6305.35 & 11.91 & 0.07 \\
\hline 2 by 4 & 110.91 & 1 & 110.91 & 0.21 & 0.69 \\
\hline 3 by 4 & 259.01 & 1 & 259.01 & 0.49 & 0.56 \\
\hline Lack of Fit & 443.87 & 6 & 73.98 & 0.14 & 0.97 \\
\hline Pure Error & 1058.46 & 2 & 529.23 & & \\
\hline Total SS & 9646.21 & 18 & & & $F$ \\
\hline
\end{tabular}



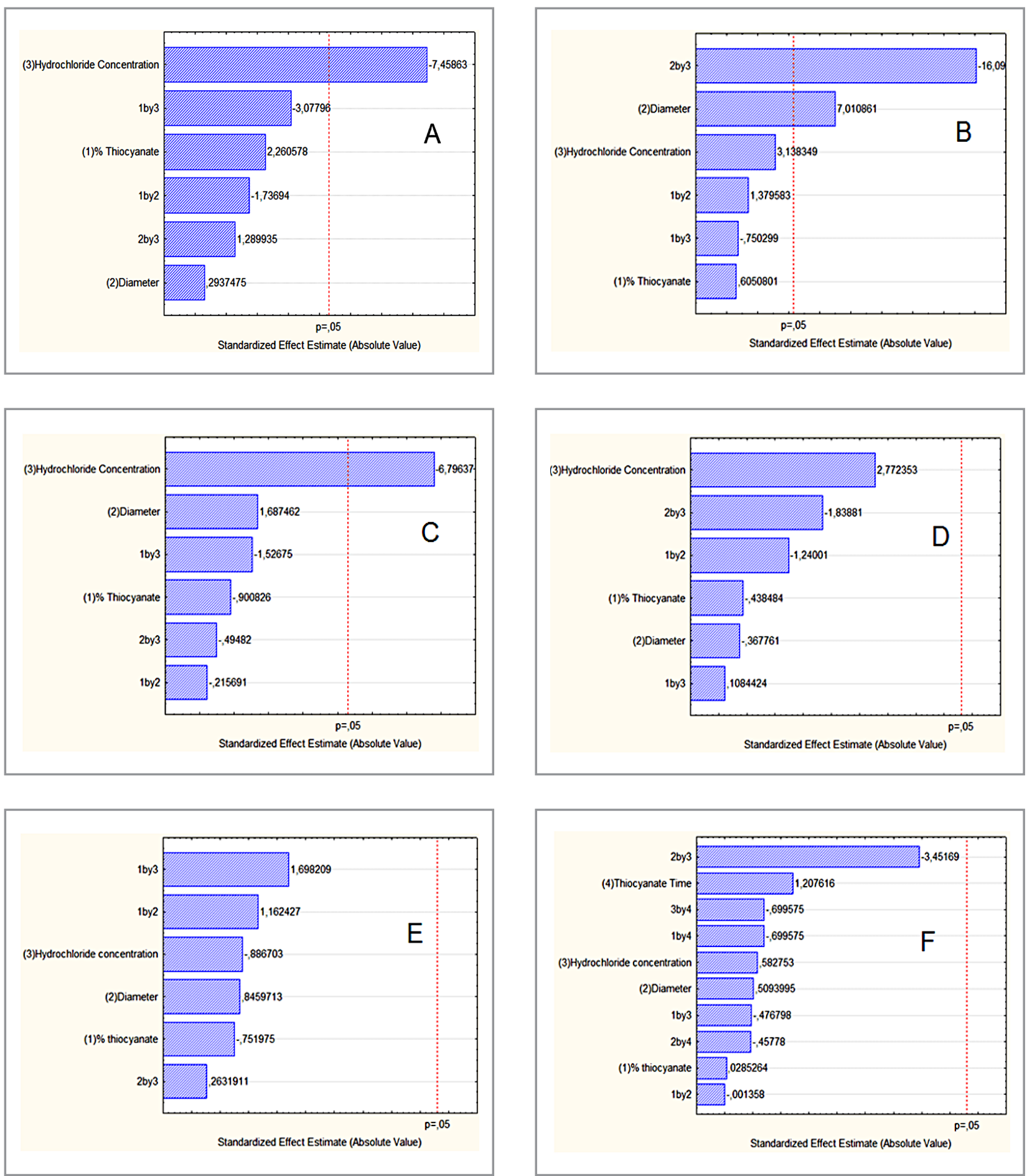

Figure 1S. Pareto charts of the six statistical models: Immediate (a), 30 min (b), 1 hour (c), 12 hours (d), 24 hours (e) and time as variable (f), respectively. 


\section{Response Surfaces Confronting Hydrochloride Concentration X Diameter}
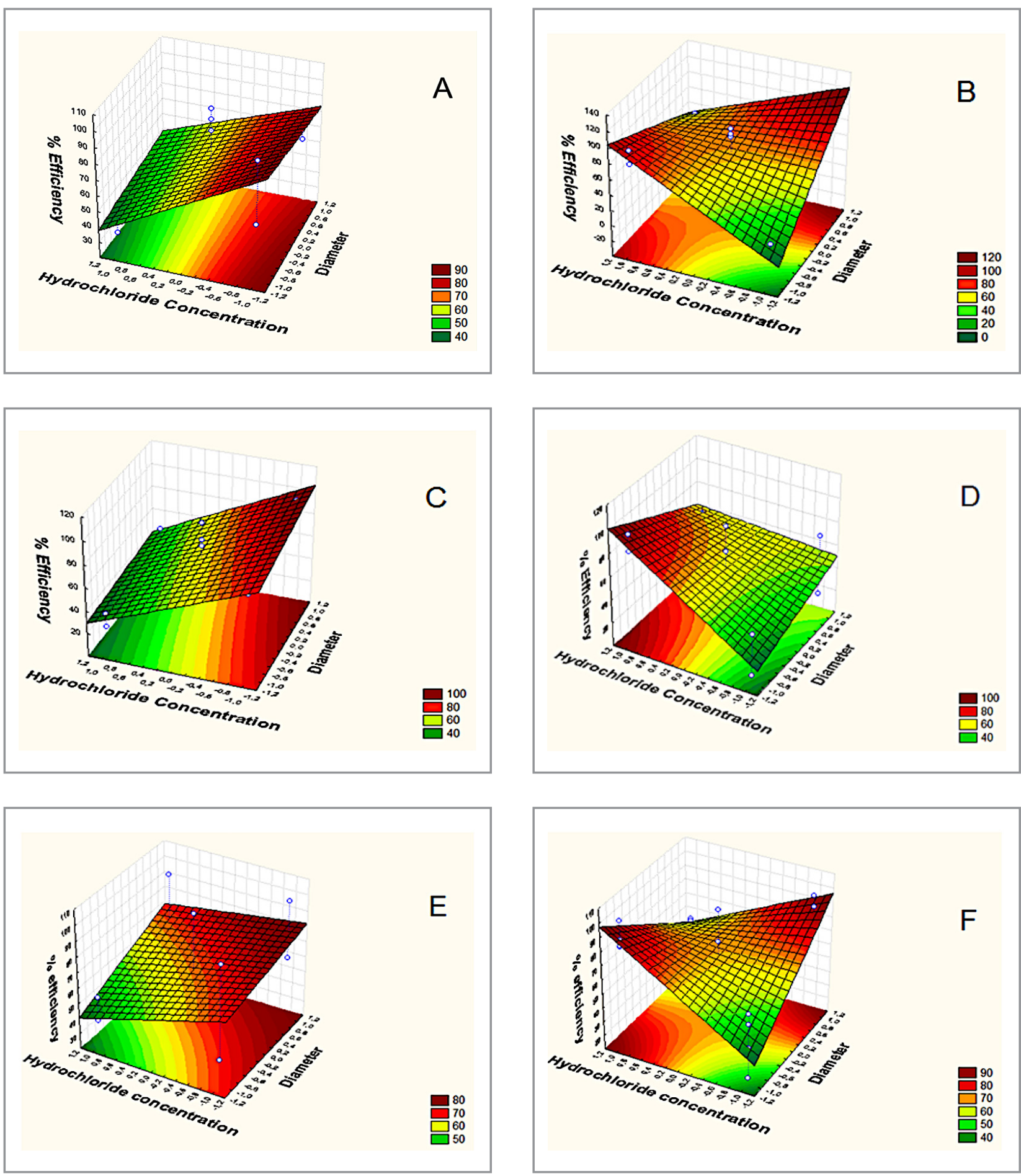

Figure 2S. Response surface graphs of the six statistical models: Immediate (a), 30 min (b), 1 hour (c), 12 hours (d), 24 hours (e) and time as variable (f), respectively. 


\section{Response Surfaces Confronting Hydrochloride Concentration X \% Thiocyanate}
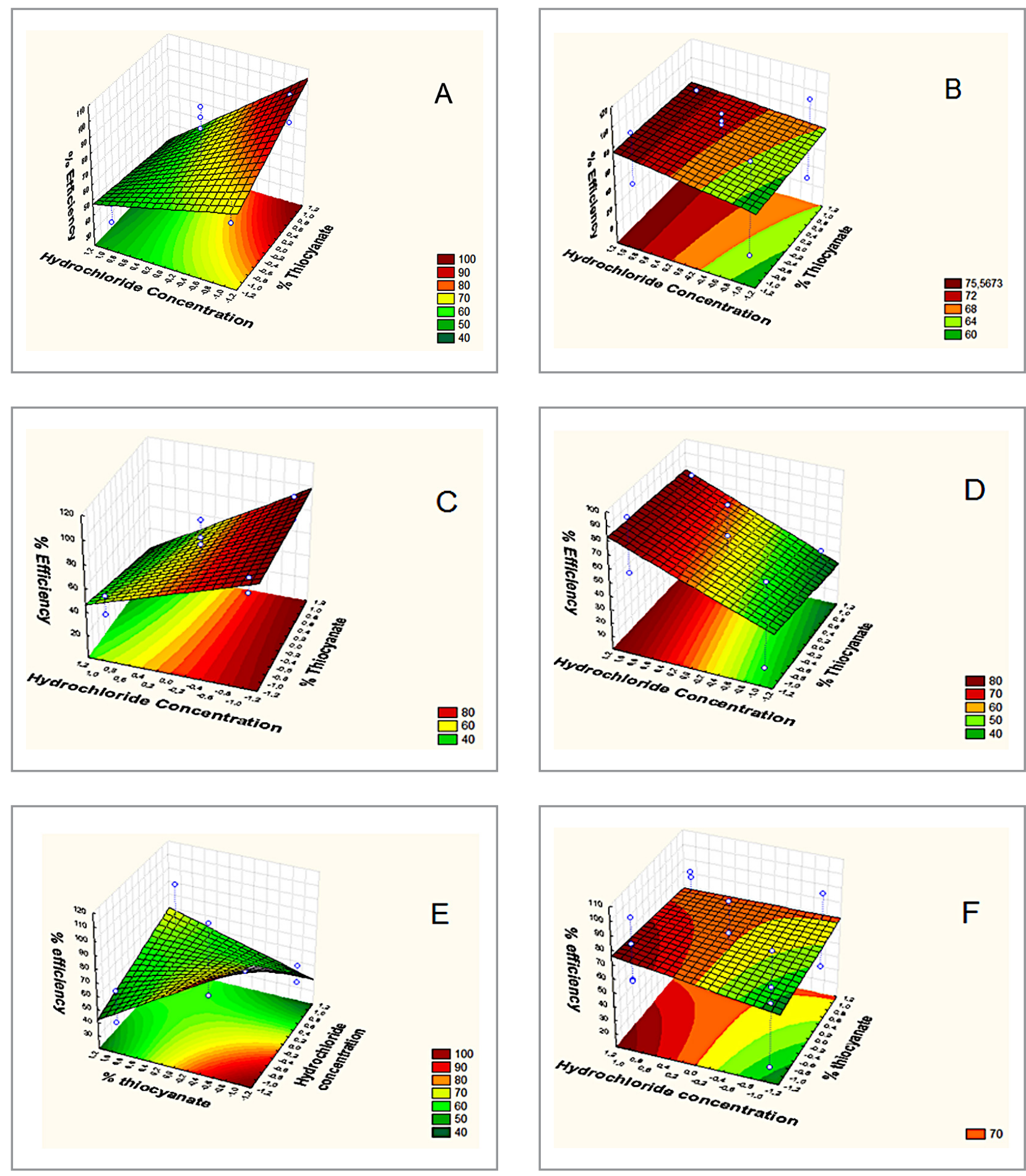

Figure 3S. Response surface graphs of the six statistical models: Immediate (a), 30 min (b), 1 hour (c), 12 hours (d), 24 hours (e) and time as variable (f), respectively. 